\title{
Regional economic resilience: concepts, empirics and a critical review
}

\begin{abstract}
Regional (economic) resilience and resilient thinking have gained considerable attention in recent years. My aim with this work is to throw light on some of the underlying aspects of regional economic resilience and resilient thinking. In the current study I give an overview of the notion, key concepts, main empirical results and planning tasks concerning regional (economic) resilience as well as outlining some of the criticisms. Finally, I provide some suggestions for studies in resilience and resilient thinking for future research agendas. The main results of the study is my own belief in the concept of regional economic resilience, and an overview and comparison of regional (economic) resilience literature and empirics that lead me to highlight some of the shortcomings of the research topic.

Keywords

Regional economic resilience - overview of concepts - overview of empirics $\bullet$ critical assessment $\cdot$ resilient thinking
\end{abstract}

(C) University of Warsaw - Faculty of Geography and Regional Studies
Balázs István Tóth

University of West Hungary, Faculty of Economics, Department of International and Regional

Economics, Hungary

e-mail: tothbalazsistvan@gmail.com

Received: 9 July 2015

Accepted: 7 September 2015
Introduction

In recent years there have been a number of attempts to explore and analyse various aspects of resilience. The term has become popular in both natural and social sciences, and due to the recent global financial crisis, has also gained considerable attention in economics and in regional science. The main motivations for this scientific enterprise, as well as its characteristic features, are currently being revealed by the scientific community. It has been amongst the latest research issues in regional economics for some years. Browsing the studies, one can find many contributions to the topic; however, both conceptualization and practical relevance concerning the topic are still affected by many uncertainties.

This study sets three goals. The primary interest is in providing a brief but well-structured overview of the notion, conceptualization and main empirical investigations of regional (economic) resilience. It is a crucial issue because the original concept of resilience inspired scholars' logic in a different way. To this end, a careful and broad analysis of the scientific literature is required. Second, this study is aimed at giving an insight into resilient thinking and the main planning tasks. The examples I give are just a small number of the examples that, in my view, verify the theoretical foundations. The third goal of the research is to report on the debates, and highlight some of the critical remarks, concerning regional resilience. The final sections definitely mirrors my own attitude; a critical judgment is produced as well the answers to questions such as "what has been achieved" and "what still needs to be clarified". The main outcome is my own belief in the concept of regional economic resilience.
The notion of regional resilience: concepts and approaches

The concept of resilience, which was initially developed by Holling (1973) as a framework for ecological research, has been applied to social and economic fields in the last few decades. The term reflects its Latin root "resiliere", which means "to leap or spring back, to recoil, to rebound, to shrink (back again)". Without doubt resilience has these days become a highly attractive catchword as well as fashionable concept (Christopherson et al. 2010; Müller 2011; Fingleton et al. 2012; Wink 2014a), and appears to hold significant analytical potential (Bristow \& Healy 2014). Although an agreed upon and unambiguous operational concept still does not exist - "resilience, as currently employed, has multiple meanings" (Simmie 2014, 104) - as well as there being no widespread agreement on the processes and factors that can be used to measure it, resilience should be regarded as a key issue and a promising scientific enterprise in the future. Obviously the issue is particularly important in economics and regional studies, especially in a period like the current one, which is the result of the recent global financial crisis. Moreover, according to Eraydin (2012), resilience might be regarded as the basis for a new planning paradigm.

Holling (1973) introduced resilience as the ability to persist within a domain in the face of change. He assumed that ecosystems are characterized by multiple locally stable equilibria, and regime shifts entail a sudden shift from one stable equilibrium to another. In line with this belief; several more accurate, but seemingly similar, interpretations and definitions have been developed and published since. For instance, according to Walker et al. $(2004,6)$ "resilience is the capacity of a system to absorb disturbance and 
reorganize while undergoing change so as to retain, essentially, the same function, structure, identity, and feedback". From this viewpoint, resilience should be regarded as the potential of a given system to preserve its configurations and functions, and suggests the structure has the ability to reorganize itself. This interpretation may be fundamentally attractive to many experts; however, there are many, further specifications regarding the "resilience of system". For instance, Pendall et al. $(2007,2)$ defined the term as follows: "When we say that a person, society, ecosystem, or city is resilient, we generally mean that in the face of shock or stress, it either rapidly 'returns to normal' (i.e. equilibrium) afterward, or at the least is not easily pushed into a 'new normal' (i.e. an alternative equilibrium)". ${ }^{1}$

By having involved societies, ecosystems and especially cities in the research, the above mentioned understanding highlights the fact that scholars and practitioners in regional science and spatial planning ought to deal with and reflect on the notion of resilience. According to Wink $(2014 a, 83)$ resilience has found its way into the discourse on regional economic development and "as the capacity to avoid, withstand or adapt to crises, has become a catchword to describe the capabilities required to cope with negative shock and adverse conditions". In addition, one may agree with Jonas $(2012,268)$, who defined resilience as an internal property of a territory, which "must always be juxtaposed with the external risks to places and regions, posed by global flows of investment, and environmental and economic crises".

While conceptualizing resilience, two main theoretical streams were defined and fundamentally distinguished. On the one hand, engineering resilience is used to refer to an underlying stable growth path to which a system (e.g. the regional economy) rebounds following a shock or a recession. In this sense the resistance and the immediate reaction of a system (e.g. a region) to disturbances, ${ }^{2}$ as well as the speed of recovery in returning to its pre-shock state, are the major issues. In many investigations, a system (region) is supposed to be in equilibrium before the shock, and resilience is discussed in relation to the stability of a system near its equilibrium. On the other hand, ecological (or ecosystem) resilience focuses on the role of disturbances in pushing a system (regional economy) into a new state. This perspective focuses mainly on how a shock persistently changes the system's (region's) behaviour (Holling 1996; Folke 2006; Simmie \& Martin 2010; Hervas-Oliver et al. 2011; Fingleton et al. 2012; Martin 2012; MacKinnon \& Derickson 2013; Cellini \& Torrisi 2014).

When discussing various frameworks of resilience, the concept of socio-economic resilience, or in other words, resilience in relation to social-ecological systems, should not be neglected. The concept incorporates the idea of adaptation, learning, self-organization and the ability to persist despite disturbance (Folke 2006). In recent years, a new consensus concerning organisational resilience has emerged as a practical response to the declining lifecycle of organisations; in order to survive and prosper in an environment of change and uncertainty, organizations must focus on resilience so as to be able to make

\footnotetext{
'In reality, a system can tend only toward 'near equilibrium'. In other words, for any continuous evolution one can ensure a 'homeostatic equilibrium' (see e.g. Kornai 1983; Lehmann-Waffenschmidt 2007).

2Disturbances to which regions or cities tend to be subject, fall into the following categories: "natural (e.g. earthquakes, volcanic eruptions, floods), economic (e.g. market shocks, financial crises), biomedical (e.g. diseases), social (e.g. preference changes, population issues, labour availability, and security), technological (e.g. industrial accidents) and political (e.g. change of government, terrorism, wars)". Interruptions occur "for a few minutes (e.g. traffic jams), hours and days (e.g. floods, hurricanes), weeks (e.g. stock market crashes), months (e.g. market cycles in housing prices) or even decades (drought, climate change, warming periods, gentrification)". Finally, disturbances vary from "local level activities to a citywide, regional, national and global scale" (Müller 2011, 4).
}

their competitive advantage adaptable (Burnard \& Bhamra 2011). ${ }^{3}$ As mentioned in previous paragraphs, regional economic resilience has also emerged and is becoming a crucial issue. The terms are used particularly in order to understand how local and regional economies are faring due to the consequences of recent economic crises (Christopherson et al. 2010; Simmie \& Martin 2010; Martin 2012; Bristow \& Healy 2014).

The approach is based on the adaptive notion of resilience, which originates in the theory of complex adaptive systems preferred by scholars working in evolutionary economic geography (Holling \& Gunderson 2002; Folke 2006; Martin \& Sunley 2007; Simmie \& Martin 2010). ${ }^{4}$ This belief may also "resonate with the notion that economic development involves resistance and adaptation as much as growth and competition" (Jonas 2012, 268). Based on the Schumpeterian argument, Simmie (2014) suggested that regional innovation systems policies contribute to the adaptation of regional economies, and therefore their resilience. In parallel with this, a key facet within the framework was emphasized through the notion of path dependency (Chapple \& Lester 2010; Hassink 2010; Simmie \& Martin 2010; Röhring \& Gailing 2011).

Martin (2012) as well as Fingleton et al. (2012) demonstrated how the concept of resilience can be combined with the idea of hysteresis in order to study the degree to which regions differ in their ability to resist or recover from shocks, and to realize whether regions that are more severely affected tend to grow more slowly than other regions. It also should be mentioned that Boschma et al. (2014) differentiated between exogenous economic resilience characterizing capabilities that cope with external shocks and to preserve regional development pathways, and endogenous economic resilience characterizing intrinsic processes; this notion underlines the evolutionary approach to analysing regional resilience.

\section{Measuring regional resilience: overview of empirics}

Empirical studies are important in understanding the real contribution of resilience debates to regional studies. A large number of empirics, by involving both qualitative and quantitative methods, have developed around the issue of regional (economic) resilience. For instance, drawing upon a series of interviews with local actors, Hervas-Oliver et al. (2011) examined the North Staffordshire industrial ceramics district's adaptive capacity to offer potential for a new trajectory. Similar methodologies (interviews, surveys) were emphasized in several other studies, as in the cases of the East Midlands (Oxborrow \& Brindley 2012), Stockholm and Rostock (Albers \& Deppisch 2013), Buffalo (New York) and Cleveland (Ohio) (Cowell 2013), Western North Carolina (Slocum \& Kline 2014), as well as through a Norwegian (Carlsson et al. 2014) and German example (Kiese \& Hundt 2014).

Other scholars argued more in favour of quantitative investigations. Pendall et al. (2012) managed to document the relationships between potential personal/household vulnerability, potentially precarious housing conditions and regional resilience based on micro data from 84 metropolitan areas across the USA. Fingleton et al. (2012) analysed the quarterly employment series for UK regions for the period 1971-2010 using the SURE (seemingly unrelated regression equation) estimation and VECM (vector error-correction model) specification. Cellini and Torrisi (2014) also

\footnotetext{
${ }^{3}$ Enterprises that are able to quickly seize competitive advantage from sudden changes in their environments, with negligible interruption to their missions and a manageable impact on their market value, as well as adapt to change in an apparently slower, more evolutionary manner; can be described as being more resilient.

${ }^{4}$ The adaptive renewal cycle or "panarchy" is a heuristic model consisting of four phases of development driven by discontinuous events and processes: period of exponential change, period of conservation and rigidity, period of readjustments and collapse and, lastly, period of re-organization and renewal. The sequence of gradual change is followed by a series of rapid changes. It is important to underline that disturbances are also part of development (Holling \& Gunderson 2002; Folke 2006).
} 
argued for this approach in the light of a very long-term analysis (1890-2009) done in Italy with regard to gross domestic product (GDP). Comparing the results of these two studies, one may observe two important outcomes and come to two conclusions: on the one hand some evidence is provided about the effect of shocks originating in different areas (Fingleton et al. 2012); on the other, justification for the concept of resilience is quite unconvincing as only a few shocks have specific impacts across regions and the recovery experience proved to be spatially homogeneous (Cellini \& Torrisi, 2014).

Other empirical investigations with regard to regional unemployment have been carried out so far. Chapple and Lester (2010) examined the success of regional labour markets in the USA. Using discriminant analysis, the authors managed to identify certain factors behind resilience (e.g. regional transformation, ability to attract immigrants, retention of manufacturing, having an innovative high-tech economy).

Champion and Townsend (2013) evaluated the change in employment and the change in the sectoral composition of employment for nine, second-order city regions of Great Britain during the 2008-2009 recession periods; then the authors contrasted the results with the outcomes of the two previous recessions. It was found that the most recent recession had less impact on city regions than the two previous recessions, in absolute terms; however, second-order city regions generally performed worse than the country as a whole.

A quantitative analysis of the Danish information and communication technology (ICT) sector was presented by Holm and Østergaard (2013); where the authors compared the differences in the patterns of growth before and after the year 2000 , in order to identify which characteristics of regional industry influenced regional industrial resilience. It was found that there was no relationship concerning growth that could be observed among the regional ICT industries; however, different sources and dimensions of resilience were recognized between Danish regions.

Based on a skill-relatedness index, Otto et al. (2014) pointed out that skill-relatedness among traditional industrial sectors in the German federal state of Saar-land, made it possible for workers to switch from industries that were more negatively affected, to less affected sectors during the recession period of 2008-2012; which increased the resilience of the regional labour market. This resilience; however, might be vulnerable in the future due to missing links with new, emerging high-technology industries in Saarland.

Using scenario building methodology by establishing an original spatial econometrics and general forecasting model $\left(\right.$ MASST $^{5}$ ), Capello et al. (2015) concluded that cities play a significant role in the resilience of regions. Economic resilience may increase, not only when the size of cities is considered, but especially with regard to the type of functions hosted in them. The authors' results showed that higher value-added activities, higher quality production factors, higher density of external linkages and cooperation networks, and better quality urban infrastructure provided greater economic resilience for cities, and for the regions hosting them.

Resilient thinking and Main planning tasks

Besides conceptualization and empirical investigations, it is also essential to rethink some of the attributes of planning, in order to be able to prepare regional and urban systems for unforeseen and unexpected disturbances. It has become more

${ }^{5}$ MASST is Macroeconomic, Sectoral, Social and Territorial model. Three versions of MASST have been introduced so far. The model comprises two blocks, one explaining national growth, and the other explaining regional differential growth. In the latest version of the model, regional growth is an endogenous process stemming from local resource endowment (regional innovation, dynamics of sectoral structure, population growth, urbanization economies and unemployment growth) (Capello \& Fratesi 2012) and more evident that in order to tackle economic, social or ecological crises and risks, a new theoretical perception in planning is required.

The importance of resilient thinking as an integrative framework that combines rational and communicative planning was stressed by Eraydin (2012), who highlighted that regions and urban areas have become vulnerable to the outcomes of economic restructuring under neoliberal and entrepreneurial principles, consumerism, changes in property markets and democratic deficits as well as to global pressures. Besides, Cruz et al. (2012) underlined that urban sprawl, polycentric development, shrinkage and the agglomeration of urban activities (compactness) are related to particular urban resilience patterns that influence urban growth and the dynamics of urban change. Moreover, according to Stumpp (2014), resilience replaces sustainability and sustainable thinking as having the potential to positively, as well as emotionally, transform political agendas and issues.

Some recent work has highlighted the outcomes of resilient thinking more precisely. For instance, by identifying some of the key factors of regional resilience (relationships, innovation and culture), Oxborrow and Brindley (2012) pointed out how small and medium sized enterprises (SMEs) in the East Midlands develop strategies to cope with recessionary ripples and structural change.

According to Albers and Deppisch (2013), spatial planning has already contributed to urban and regional resilience based on the results of two exploratory studies (Stockholm and Rostock).

Despite ongoing challenges in Buffalo (New York) and in Cleveland (Ohio), leaders have utilized economic development planning to adapt to the evolving challenges of deindustrialization; both regions foresaw moves towards a stage where resilience is high and innovation is emphasized (Cowell 2013).

As a remarkable example of a regional response to recession, the role of the West Midlands Regional Taskforce was examined in detail by Bailey and Berkeley (2014). According to the authors, the organization delivered a number of outcomes in its regional response to the recession.

Based on the long-term effects of ten Norwegian restructuring programs, which covered changes in employment, entrepreneurial activity as well as soft factors such as endogenous development capacity, Carlsson et al. (2014) emphasized that long-term growth and an increase in industrial and relational diversity could be observed; however, the restructuring program policy instruments seemed to enhance resilience in diverse ways.

With regard to the contribution of German cluster policies to regional resilience, it was found that a great variety of regional specialization could be fostered (Kiese \& Hundt 2014), and the authors underlined that the process depended on the nature of the cluster policy portfolios, the degree of bottom-up governance, coherence, complexity and institutionalization.

Based on a case study in the UK, Simmie (2014) emphasized that the location of NUTS 1 regions $^{6}$ affects their relative adaptability, and therefore their economic resilience; thus certain territories (e.g. the South East) have benefitted from the agglomeration effects of successful growth poles and from fully functioning regional innovation systems.

Sagan and Masik (2014) highlighted some functional and structural aspects of regional resilience in the Pomorskie region with regard to economic, population and place characteristics as well as the community and the role of regional policy. It was found that community and social capital is undoubtedly one of the strongest attributes of regional resilience; however, richness in ecosystem services also strengthens resilience considerably.

${ }^{6}$ NUTS is Nomenclature des Unités Territoriales Statistiques, a geocode standard for referencing the subdivision of countries for statistical purposes, developed and regulated by the European Union. 
Regional resilience in academic debates

It should not be ignored that voices of criticism against resilience in general, as well as against regional (economic) resilience, have emerged among scholars in the past few years. The regional resilience concept has been tossed around with increasing frequency in economic development circles with remarkable little grounding or connection to regional development literature or research itself. Researchers have made several critical remarks concerning the description, theoretical foundation and relevance of resilience, as the term is simultaneously used in a broad range of topics and therefore is not appropriate for a concise and well-founded concept (Brand \& Jax 2007; Hassink 2010; Müller 2011; Bailey \& Berkeley 2014).

Moreover, one may distinguish between several different categories that determine "resilience to what", and it should also be stressed that disturbances may occur and vary both on a temporal and a spatial scale. A lack of understanding can also be observed concerning the processes and factors that make regions and cities resilient, yet others vulnerable (Müller 2011; Röhring \& Gailing 2011). In line with this, precise operational factors, which affects and determines an area's resilience, is still missing. In order to provide results about the characteristics of shocks, and to understand which regions are resistant or are able to recover as well as renew their growth, quantitative or rather mixed methods and dynamic approaches are required (Müller 2011; Bristow \& Healy 2014; Wink 2014b). In addition, a gap still exists between the intense theoretical discussion and the use of resilience-based thinking in planning practice (Albers \& Deppisch 2013; Wink 2014b).

Other shortcomings can be identified in the existing literature. For instance, the majority of empirical studies focus only on the short-term impacts of crises instead of estimating the long-term costs associated with crises (Wink 2014b; Capello et al. 2015). Another shortcoming relates to the fact that only a few of the previous studies took into consideration the different spatial characteristics of areas that might be of help in exploring the resilience of their economies (Capello et al. 2015).

The role played by both engineering and ecological resilience seems to be explained in different ways. According to Holm and Østergaard (2013) as well as Cowell (2013), engineering resilience is imperfect and misleading; an economy is said to be resilient if the relevant performance indicator is either relatively unaffected by the disturbance or returns to the pre-disturbance level relatively quickly and easily. Even ecological resilience ought to be treated with reserve as it recognizes that equilibrium is multiple rather than singular (Simmie \& Martin, 2010). It is also important to underline that resilience refers to a process of "bouncing back" from disturbances rather than immunity from harm (Norris et al. 2009). MacKinnon and Derickson (2013) offered a shift from resilience to resourcefulness, ${ }^{7}$ which may better suit the practical issues and challenges; however, the latter approach still has many uncertainties.

Conclusions: "quo vadis" regional economic resilience?

Recently resilience and related research areas have been rapidly gaining ground. The term aims to establish and discuss the features of a new theoretical and conceptual approach, both for natural and social sciences. Resilience has also become visible in economics and in regional studies as well as in spatial planning in recent times. Regional resilience is particularly

\footnotetext{
${ }^{7}$ Resourcefulness seeks to transform social relations in more progressive, anticapitalist and socially just ways, as well as redress issues of recognition and redistribution. Resourcefulness focuses on the uneven distribution of resources within and among communities, and maintains openness to the possibilities of community self-determination through local skills and knowledge. The approach emphasizes forms of learning and mobilization based upon local priorities and needs as identified and developed by community activists and residents (MacKinnon \& Derickson 2013).
}

important in providing an understanding of how local communities act in the context of environmental, economic or social changes. The concept of regional (economic) resilience is a promising and attractive approach for some researchers; however, it still remains an alternative and fuzzy framework, and some scholars tend not to use the idea of regional resilience. The concept has been adopted from other fields so; consequently, researchers with different backgrounds understand regional resilience in diverse ways. This fact obviously affects their belief in the characteristic of resilience and the application of the concept in practice and planning. Notwithstanding this, there is an increasing need to explore and discuss the concept of regional (economic) resilience, especially in periods of shock and recessions, both in science and in practice.

As the survey outlines above, there are substantial differences in the way the resilience concept is defined and operationalized; different theoretical streams for defining, conceptualizing and measuring regional (economic) resilience can be identified. Although there have been promising attempts to quantify regional (economic) resilience and there is now some evidence of how resilience influences spatial thinking and vision, there is also still much uncertainty concerning the complex processes that lead to disturbances, and clearly, much more research is required in examining the importance of local processes and spatial factors for economic resilience, regarding disturbance and recovery.

In my opinion, the etymological and ecological background and parallels are a useful foundation, but scholars run into trouble when they attempt to become more concrete about the implications for regional economic development. Complex adaptive systems, "panarchy" and movement towards (near) equilibrium are promising connections; however, these concepts themselves have important and deep roots in the economic development literature, which are only tenuously linked to resilience itself.

In addition, from my point of view, the key problem of applied studies lies in the way resilience is analysed. Empirical issues focus mainly on the resilience of economic indicators in various spatial contexts instead of estimating the resilience of an economic area as a whole system. Moreover, besides the conventional economic performance indicators used in economic analyses such as the employment or unemployment rate, gross domestic product (GDP), gross value added (GVA) and disposable income - there is a need to understand the role of the human and social perception of disturbances as well as to avoid and overcome further damages from disturbances. One may imagine a situation, where 'objective' data showed resilience, but inhabitants of an area and the local society do not express pleasure or satisfaction. This means that several endogenous sources and spatial factors should be involved in resilience studies in order to get a broader and clearer picture of the complex interrelationships between productivity, stability and local communities. Greater efforts in terms of data collection should be made in the future to explore and explain other elements of regional potential, especially the soft ones (e.g. human capital, creativity, innovative spirit, relational capital, social capital, participation, voluntary activities etc.). Estimating new, mainly intangible forms of (economic) interactions will be relevant in order to deal with challenges in this context.

The topic is of strong practical relevance, despite the critical comments. Even in the short term, practitioners have to consider whether resilient thinking is an appropriate framework for spatial planning and territorial (regional and urban) development, although the contribution depends on resilience principles, objectives and measures. Current findings call for a set of considerations that may be taken into account in formulating and implementing economic development strategies for regions. Without a doubt, 
there is no common model or approach guaranteeing success for regional economic development (Stimson et al. 2006). Regional economic development policy now needs to pay more attention to regional potentials in order to strengthen regional economic development. In reality; however, there could be significant delays in planning and implementation; both the features of a crisis and the attributes of regional potentials may change, or the recession may be over by the time comprehensive statistical data is at hand to give detailed suggestions to practitioners.

There should be an increased recognition that sustainable solutions and sustainable thinking are not enough. To ensure regional economic development there is also a need for resilient thinking, which means that a new synthetic framework for spatial planning and regional economic development should not be separate from resilient concepts and frameworks. There is also a great need to prepare social and economic interactions (e.g. regional business concentrations, strategic alliances etc.) as well as local communities in order to stand against economic recessions and be self-sufficient. Agglomeration economies need to build upon market intelligence, which involves risk management capability of enterprises and industries. One of the most difficult tasks is to convince scholars and practitioners of the actual value of the concept in framing particular aspects of regional economic development.

\section{Acknowledgements}

This work was supported by the Balassi Institute under Campus Hungary Program (B2/4H/12066) at the Vienna University of Technology, Vienna.

\section{References}

Albers, M \& Deppisch, S 2013, 'Resilience in the Light of Climate Change: Useful Approach or Empty Phrase for Spatial Planning?', European Planning Studies, vol. 21, no 10, pp. 1598-1610.

Bailey, D \& Berkeley, N 2014, 'Regional Responses to Recession: The Role of the West Midlands Regional Taskforce', Regional Studies, vol. 48, no. 11, pp. 1797-1812.

Boschma, R, Balland, PA \& Kogler DF 2014, 'Relatedness and technological change in cities: the rise and fall of technological knowledge in US metropolitan areas from 1981 to 2010', Industrial and Corporate Change, Available from: <http://icc.oxfordjournals.org/content/early/2014/05/09/icc. dtu012> [15 March 2015].

Brand, FS \& Jax, K 2007, 'Focusing the Meaning(s) of Resilience: Resilience as a Descriptive Concept and Boundary Object', Ecology and Society, vol. 12, no. 1, Available from: <http:// www.ecologyandsociety.org/vol12/iss1/art23> [23 October 2014].

Bristow, G \& Healy, A 2014, 'Regional Resilience: An Agency Perspective', Regional Studies, vol. 48, no. 5, pp. 923-935.

Burnard, K \& Bhamra R 2011, 'Organisational resilience: development of a conceptual framework for organisational responses', International Journal of Production Research, vol. 49 , no. 18 , pp. 5581-5599.

Capello, R, Caragliu, A \& Fratesi, U 2015, 'Spatial heterogeneity in the costs of the economic crisis in Europe: are cities sources of regional resilience?', Journal of Economic Geography, Available from: <http://joeg.oxfordjournals.org/ content/early/2015/01/20/jeg.lbu053> [15 March 2015].

Capello, R \& Fratesi, U 2012, 'Modelling Regional Growth: An Advance MASST model', Spatial Economic Analysis, vol. 7, no. 3, pp. 293-318.

Carlsson, E, Steen, M, Sand, R \& Nilsen SK 2014, 'Resilient peripheral regions? The long-term effects of ten Norwegian restructuring programmes', Norsk Geografisk Tidsskrift Norwegian Journal of Geography, vol. 68, no. 2, pp. 91-101.

Cellini, R \& Torrisi, G 2014, 'Regional Resilience in Italy: A Very Long-Run Analysis', Regional Studies, vol. 48, no. 11, pp. 1779-1796.

Champion, T \& Townsend, A 2013, 'Great Britain's second-order city regions in recessions', Environment and Planning A, vol. 45 , no. 2 , pp. $362-382$

Chapple, K \& Lester, TW 2010, 'The resilient regional labour market? The US case', Cambridge Journal of Regions, Economy and Society, vol. 3, no. 1, pp. 85-104.

Christopherson, S, Michie, J \& Tyler, P 2010, 'Regional resilience: theoretical and empirical perspectives', Cambridge Journal of Regions, Economy and Society, vol. 3, no. 1, pp. 3-10.
Cowell, MM 2013, 'Bounce back or move on: Regional resilience and economic development planning', Cities, vol. 30, pp. 212-222.

Cruz, SS, Costa, JPTA, de Sousa, SÁ \& Pinho, P 2012, 'Urban Resilience and Spatial Dynamics', in Resilient Thinking in Urban Planning, eds. A Eraydin \& T Taşan-Kok, Springer, Dordrecht, Heidelberg, New York \& London, pp. 53-69.

Eraydin, A 2012, 'Resilient Thinking for Planning', in Resilient Thinking in Urban Planning, eds. A Eraydin \& T Taşan-Kok, Springer, Dordrecht, Heidelberg, New York \& London, pp. 17-37.

Fingleton, B, Garretsen, H \& Martin, R 2012, 'Recessionary Shocks and Regional Employment: Evidence on the Resilience of U.K. Regions', Journal of Regional Science, vol. 52, no. 1, pp. 109-133.

Folke, C 2006, 'Resilience: The emergence of a perspective for social-ecological systems analysis', Global Environmental Change, vol. 16, no. 3, pp. 253-267.

Hassink, R 2010, 'Regional resilience: a promising concept to explain differences in regional economic adaptability', Cambridge Journal of Regions, Economy and Society, vol. 3 , no. 1 , pp. $45-58$.

Hervas-Oliver, JL, Jackson, I \& Tomlinson, PR (2011) "May the ovens never grow cold': regional resilience and industrial policy in the North Staffordshire ceramics industrial district - with lessons from Sassoulo and Castellon', Policy Studies, vol. 32 , no. 4, pp. 377-395.

Holling, CS 1973, 'Resilience and Stability of Ecological Systems', Annual Review of Ecology and Systematics, vol. 4 , pp. 1-23.

Holling, CS 1996, 'Engineering Resilience versus Ecological Resilience', in Engineering Within Ecological Constraints, ed. PC Schulze, National Academy Press, Washington, D.C., pp. 31-43.

Holling, CS \& Gunderson, LH 2002, 'Resilience and Adaptive Cycles', in Panarchy: Understanding Transformations in Human and Natural Systems, ed. CS Holling \& LH Gunderson, Island Press, Washington, D.C., pp. 25-62.

Holm, JR \& Østergaard, CR 2013, 'Regional Employment Growth, Shocks and Regional Industrial Resilience: A Quantitative Analysis of the Danish ICT Sector', Regional Studies, vol. 49 , no. 1 , pp. $95-112$.

Jonas, AEG 2012, 'Region and place: Regionalism in question', Progress in Human Geography, vol. 36, no. 2, pp. 263-272.

Kiese, M \& Hundt, C 2014, 'Cluster Policies, Organising Capacity and Regional Resilience: Evidence from German Case Studies', Raumforschung und Raumordnung, vol. 72, no. 2, pp. 117-131. 
Kornai, J 1983, 'Equilibrium as a Category of Economics', Acta Oeconomica, vol. 30, no. 2, pp. 145-159.

Lehmann-Waffenschmidt, M 2007, Economic Evolution and Equilibrium: Bridging the gap, Springer, Berlin \& Heidelberg.

MacKinnon, D \& Derickson, KD 2013, 'From resilience to resourcefulness: A critique of resilience policy and activism', Progress in Human Geography, vol. 37, no. 2, pp. 253-270.

Martin, R 2012, 'Regional Economic Resilience, Hysteresis and Recessionary Shocks', Journal of Economic Geography, vol. 12, no. 1, pp. 1-32.

Martin, R \& Sunley, P 2007, 'Complexity thinking and evolutionary economic geography', Journal of Economic Geography, vol. 7 , no. 5, pp. 573-602.

Müller, B 2011, 'Urban and Regional Resilience - A New Catchword or a Consistent Concept for Research and Practice?', in Urban Regional Resilience: How do Cities and Regions Deal with Change?, ed. B. Müller, Springer, Dordrecht \& Heidelberg \& New York \& London, pp. 1-13.

Norris, FH, Tracey, M \& Galea, S 2009, 'Looking for resilience: Understanding the longitudinal trajectories of responses to stress', Social Science \& Medicine, vol. 68, no. 12, pp. 2190-2198.

Otto, A, Nedelkoska, L \& Neffke, F 2014, 'Skill-relatedness and Resilienz: Fallbeispiel Saarland', Raumforschung und Raumordnung, vol. 72, no. 2, pp. 133-151.

Oxborrow, L \& Brindley, C 2012, 'Regional resilience in recessionary times: a case study of the East Midlands', International Journal of Retail \& Distribution Management, vol. 40, no. 11 , pp. 882-899.

Pendall, R, Foster, KA\& Cowell, M 2007, 'Resilience and Regions: Building Understanding of the Metaphor', Institute of Urban and Regional Development Working Paper 2007-12, Available from: <www.escholarship.org/uc/item/4jm157sh. pdf> [23 October 2014].

Pendall, R, Theodos, B \& Franks, K 2012, 'Vulnerable people, precarious housing, and regional resilience: an exploratory analysis', Housing Policy Debate, vol. 22, no. 2, pp. 271296.
Röhring, A \& Ludger, G 2011, 'Path Dependency and Resilience - The Example of Landscape Regions', in Urban Regional Resilience: How do Cities and Regions Deal with Change?, ed. B. Müller, Springer, Dordrecht \& Heidelberg \& New York \& London, pp. 79-88.

Sagan, I \& Masik, G 2014, 'Economic resilience. The Case Study of Pomorskie Region', Raumforschung und Raumordnung, vol. 72, no. 2, pp. 153-164.

Simmie, J 2014, 'Regional Economic Resilience: A Schumpeterian Perspective', Raumforschung und Raumordnung, vol. 72, no. 2, pp. 103-116.

Simmie, J \& Martin, R 2010, 'The economic resilience of regions: towards an evolutionary approach', Cambridge Journal of Regions, Economy and Society, vol. 3, no. 1, pp. 27-43.

Slocum, S \& Kline, C 2014, 'Regional resilience: opportunities, challenges and policy messages from Western North Carolina', Anatolia: An International Journal of Tourism and Hospitality Research, vol. 25, no. 3, pp. 403-416.

Stimson, RJ, Stough, RR \& Roberts, BH 2006, Regional Economic Development. Analysis and Planning Strategy, Springer, Berlin \& Heidelberg.

Stumpp, EM 2014, 'New in town? On resilience and "Resilient Cities"', Cities, vol. 32, pp. 164-166.

Walker, B, Holling, CS, Carpenter, SR \& Kinzig, A 2004, 'Resilience, Adaptability and Transformability in Socialecological Systems', Ecology and Society, vol. 9, no. 2, Available from: <http://www.ecologyandsociety.org/vol9/ iss2/art5> [23 October 2014].

Wink, R 2014a, 'Regional Economic Resilience: Policy Experiences and Issues in Europe', Raumforschung und Raumordnung, vol. 72, no. 2, pp. 83-84.

Wink, R 2014b, 'Regional Economic Resilience: European Experiences and Policy Issues', Raumforschung und Raumordnung, vol. 72, no. 2, pp. 85-91. 